\title{
Treatment of Travel Expenses by Golf Course Patrons: Sunk or Bundled Costs and the First and Third Laws of Demand
}

\author{
Matthew T. Brown', Daniel A. Rascher ${ }^{2}$, Chad D. McEvoy ${ }^{3}$, and Mark S. Nagel ${ }^{1}$ \\ ${ }^{1}$ University of South Carolina \\ ${ }^{2}$ University of San Francisco \\ ${ }^{3}$ Illinois State University
}

Matthew T. Brown is an associate professor in the Department of Sport and Entertainment Management. His research focuses on sport business management and sport finance.

Daniel A. Rascher is the director of academic programs and an associate professor in the sport management program. His research focus includes sport economics and sport finance.

Chad D. McEvoy is an assistant professor of sport management. His research interests include sport finance and sport marketing. Mark S. Nagel is an associate professor in the Department of Sport and Entertainment Management. His research focuses on sport finance and sport marketing.

\begin{abstract}
To attract golf patrons, sport managers must understand consumption patterns of the golfer. Importantly, the treatment of travel costs must be understood. According to the Alchian-Allen (1964) theorem, golfers treat travel costs as bundled costs (third law of economic demand) whereas classical consumer theory indicates that golfers treat travel costs as sunk costs (first law of economic demand). The purpose of this study was to determine if golf patrons treated travel costs as sunk costs or if they treated travel costs as a bundled cost. Data from a survey of course patrons in Ohio support the treatment of travel costs as bundled costs by golf course patrons, especially those classified as tourists. The strong, positive correlation found between distance traveled and the cost of greens fees enables managers to utilize geographic segmentation in choosing to whom to market their course based upon their product's price compared to area competitors.
\end{abstract}

Keywords: Alchian-Allen Theorem, Third Law of Demand, Golf Tourism, Bundling

Outdoor enthusiasts visit Ohio each year in order to participate in activities like hunting, fishing, camping, and sport. In particular, golfers represent an important and growing segment of the tourism market in Ohio. The state boasts more than 750 public and private golf courses, ranking sixth nationally in the number of private courses and sixth in public courses. Of these courses, a majority (555) had open access, with $77 \%$ of these courses under private ownership and 23\% under public ownership. The remaining courses had restricted access as they were owned by members clubs (National Golf Foundation, 2003). Further, in 2002, there were over 37 
million golfers in the United States and over six million in Ohio, according to the National Golf Foundation. These golfers played more than 24 million rounds in Ohio, while 520 million rounds were played nationally.

The Ohio Golf Course Owners Association (2003) reported that golfers spent $\$ 2.7$ billion during 2002 on golf and activities related to their playing of golf within the state. Further, $9.3 \%$ of those playing a round in Ohio were classified as tourists. These golf tourists played $12.6 \%$ of all rounds within the state. Of the $\$ 2.7$ billion total spent by golfers in 2002, $\$ 321$ million was spent by tourists. This was approximately $8 \%$ of all recreation and attraction tourism spending in the state of Ohio.

For golfers, price, course type, style, location, and number of holes are important factors that affect the choice of which course to play (Hicks, 2006). With regard to price, the cost to play a course may affect the number of rounds played at that course. For example, two public golf courses are located within the same community. The greens fee at Course A is $\$ 50$ and the greens fee at Course B is $\$ 100$. One might assume that residents living in that community would be more likely to play Course A than Course B, or they would play Course A more often than Course B, because Course A is half the cost of Course B.

The same decision regarding choice and price made by resident golfers may not be made by golfers visiting the community, however. If a person visiting the community spent $\$ 200$ on travel and lodging costs to come from a distance, the cost for a great golf vacation in the community would be $\$ 300$ if he chose to play Course B as a part of that golf vacation. The cost for an average golf vacation would be $\$ 250$ if he chose to play Course A. Thus, by paying $20 \%$ more, a tourist can have a great vacation, not an average one. A local would have to pay $100 \%$ more to have a great golf day rather than an average one. Based upon the Alchian-Allen theorem, an assumption can be made that the visiting golfer would be more likely to play Course $\mathrm{B}$, the more expensive course, as compared to the local golfer because the relative cost of playing Course $\mathrm{B}$ as compared to Course A is less for the visitor.

\section{Alchian-Allen Theorem}

The Alchian-Allen theorem, developed by Armen Alchian and William Allen (1964), states that as a fixed cost is added to the price of two products, the more expensive product becomes cheaper relative to the less expensive product. In their original writing, the two compared the consumption of grape types in California and New York. Using their original example, choice grapes may be purchased for $\$ 0.10$ per pound, and standard grapes (poorer quality) may be purchased for $\$ 0.05$ per pound in California. If a person in California wanted to purchase a pound of choice grapes, he would have to sacrifice two pounds of standard grapes. But if equal quantities of standard and choice grapes are shipped to New York, the relative cost of the grapes changes. In New York, $\$ 0.05$ per pound of grapes, regardless of grape type, must be added to the price due to shipping costs. Therefore, in New York, choice grapes sell for $\$ 0.15$ per pound and standard grapes sell for $\$ 0.10$ per pound. A person purchasing choice grapes in New York would have to sacrifice 1.5 pounds of standard grapes. Therefore, because of the lower relative price (1.5:1 in New York compared to 2:1 in California), consumption of choice grapes in New York relative to standard grapes will be higher than in California.

Borcherding and Silberberg (1978) found support of the Alchian-Allen theorem. In their paper, they noted that in addition to the transportation costs added to the total cost of the product, such as was added to the price of grapes in New York, transportation costs can be undertaken by the consumer as well. Utilizing transportation expenses as fixed costs of consumption, the authors noted that tourists visiting Maine typically eat better lobster than people who live in Maine.

As stated by Bertonazzi, Maloney, and McCormick (1993), the transportation costs to bring the lobster to the consumer, as discussed in Borcherding and Silberberg (1978), is bundled with the quality cost of the lobster. However, the transportation costs of bringing the consumer to the lobster is purchased separately and sequentially from the lobster's quality cost. In their paper, Bertonazzi et al. wanted to determine if rational consumers ignore the sunk cost of travel when making quali- 
ty choices. For instance, an Oregonian travels to Florida on vacation. After arriving in Florida, she chooses to eat at an inexpensive restaurant as compared to an expensive restaurant because the restaurant choice is separate from the choice of planning the trip to Florida. Here, the Oregonian acting as an ultra-rational consumer has ignored the fact that she has already spent a lot of money to get to Florida for her vacation.

The purpose of the Oregonian's vacation may also have affected her restaurant choice, though. If the purpose of her vacation was to bring the family to Disney World, it may appear that her meal choice was ultra-rational, when actually she decided to eat at a less expensive restaurant in order to spend more on entertainment. Here the purpose of the trip was a nice family vacation. However, if the purpose of the trip was an anniversary celebration with her husband, she may have constantly eaten at nice restaurants. Meals in this example were important to making the trip a nice anniversary vacation. So for the Oregonian, the sunk costs of travel did not affect meal choice, the purpose of the vacation did. However, the sunk costs of travel may have affected the overall, bundled vacation choices regardless of trip purpose.

In sport, Bertonazzi et al. (1993) tested the AlchianAllen theorem to determine if consumers ignore the sunk costs of travel when making quality choices. The authors studied Clemson University football season ticket purchase decisions from the 1986 and 1987 seasons. From the athletic department's database, the authors were able to obtain information regarding the number of season tickets purchased by the consumer, the quality of the tickets purchased, and the address of the purchaser. Using a metric to calculate travel costs to the game based upon the consumer's zip code, the authors affirmed the Alchian-Allen theorem as it applies to consumer travel costs and provided support for the work of Borcherding and Silberberg (1978). They found that for college football fans at Clemson University, the fans that traveled the farthest, or had the greatest sunk costs, chose the most expensive season tickets. In fact, Bertonazzi et al. found the theorem to be so broad and pervasive that they stated it qualifies as the third law of demand.

One potential flaw with the Bertonazzi et al. (1993) study is that they did not control for the degree of fanati- cism for Clemson University football. It may be that people who live farther away and buy tickets for football games are more passionate fans than those who live close and buy tickets. To choose to travel great distances for Clemson football games might mean that the person traveling really likes Clemson football, as a person living close by the university has lower opportunity costs of going to the game. This does not imply, however, that people who live farther away from the university like Clemson football more. It simply means that not all people who live farther away like Clemson football more than those who live close by, but those who live farther away and buy season tickets must really like Clemson football since their opportunity costs are greater. Therefore, these people buy good tickets simply because they really like Clemson football and the travel distance and costs have little or nothing to do with their purchase decision.

\section{The Treatment of Travel Costs}

Despite support for the Alchian-Allen theorem, it may be argued that based upon consumer theory the cost of travel adds no value to the products being offered to the consumer. Therefore, consumers of golf, as indicated in the earlier example, would treat travel costs as sunk costs and truly separate their course quality purchase decision from their travel cost decision. In other words, once the tourist arrives in the community, he can pay half as much to play Course A, \$50, as compared to Course B, $\$ 100$. If, however, consumers bundle the travel and course quality decision together, the golf tourist would have a $\$ 300$ great or a $\$ 250$ average golf vacation respectively.

\section{Travel Costs as Sunk Costs}

Classical consumer theory adds further support to the notion that golf consumers would treat travel costs as sunk costs. To maximize utility, the amount of each product to purchase is based upon the relative marginal utilities gained from each product and the relative prices of each product. For example, a golf consumer has $\$ 600$ to spend on a golf vacation. If it is assumed that he will spend $\$ 300$ for travel, lodging and food, $\$ 300$ remains to be spent on golf. Here, Course $Y$, the high end course, costs $\$ 100$ to play while Course $\mathrm{X}$, the average course, costs $\$ 50$ to play. Furthermore, assume that the con- 
sumer gains more from playing Course $\mathrm{Y}$ than Course X. A suitable utility function is $\mathrm{U}=\mathrm{f}(\mathrm{X}, \mathrm{Y})=2 \log \mathrm{X}+\log \mathrm{Y}$. The utility maximizing solution under classical consumer theory is for the consumer to play two rounds of golf at Course X and two rounds of golf at Course Y. Therefore, classical consumer theory has $\mathrm{MUx} / \mathrm{MUy}=\mathrm{MRS}=$ $\mathrm{Px} / \mathrm{Py}=1 / 2$. This implies that there is a certain mix of Course $\mathrm{X}$ and Course $\mathrm{Y}$ being played, $(1 / \mathrm{X}) /(2 / \mathrm{Y})=$ $0.5^{\star} \mathrm{Y} / \mathrm{X}$. Thus, for the equation to be true, the golfer must play equal rounds of golf at Course $\mathrm{X}$ and Course $\mathrm{Y}$. This is not surprising when one realizes that the price of Course $\mathrm{Y}$ is twice that of Course $\mathrm{X}$, yet the utility gained from playing Course $\mathrm{Y}$ is twice that of Course X. As a result, the two cancel and lead to an equal amount of rounds being played at Course X and Course Y. Yet, if the golfer bundles, he would play more of Course Y than Course X.

\section{Travel Costs as Bundled Cost}

For the golf tourist, the decision to play Course $\mathrm{X}$ or Course $\mathrm{Y}$ hinges on whether or not the goods - travel and course quality-are defined as separable. While consumer theory indicates that they would be separate, examples from the works supporting the Alchian-Allen theorem indicate that the travel and quality expenditures are not. From Alchian and Allen's (1964) work, it can be seen that the cost of shipping grapes from California to Los Angeles is not separable from the cost of the grapes themselves. The store in New York faces the total cost of purchasing a shipment of grapes, not the separate costs of shipping and quality of grapes. Borcherding and Silberberg (1978) and Bertonazzi et al. (1993) provide support and show that the costs of the goods are not treated as separable by the consumer, whether incurred by the seller or purchaser.

Becker (1971) stated that people purchase vacations, not airline tickets, hotel nights, entertainment options, etc. Each of these individual components is an input into the composition of a product that individuals desire to consume: a vacation. So, reflecting back to the Oregonian traveling to Florida on vacation, traveling across the country on vacation would indicate a major vacation that would be consistent with a menu of higher priced activities in Florida. According to Becker then, the Oregonian should decide to consume a menu of higher priced (more expensive) goods and services.

Therefore, golf consumers purchase golf vacations, not travel, hotel, food, and rounds of golf separately. Classical consumer theory would posit the consumer with the option of paying twice as much to play the high-end golf course versus the average golf course, for the example given previously. According to Becker, the golf consumer is faced with paying $\$ 350$ for an average golf vacation ( $\$ 300$ in travel expenses and $\$ 50$ in quality expenses for one round of golf) or $\$ 400$ for a high-end golf vacation (\$300 in travel expenses and $\$ 100$ in quality expenses for one round of golf). If consumers do not treat sunk costs as such, or alternatively, if the consumers bundle all of the intermediate goods (travel, lodging, food, etc.) together into a golf vacation product, then they face a ratio of prices of $\mathrm{Px} / \mathrm{Py}=350 / 400=0.875$. This is a higher ratio than the 0.5 faced under classical consumer theory. Given that MRS $=0.5^{\star} \mathrm{Y} / \mathrm{X}$, the ratio of rounds of golf of Course Y to Course X (Y/X) needs to be 1.75. Therefore, as the cost of playing golf at the high quality course decreases relative to the cost of playing at the average course, the optimal ratio rounds of golf of Course $\mathrm{X}$ to Course Y decreases.

Golf consumers who bundle the entire vacation together are more likely to play the expensive golf course compared to golf consumers who separate the decisions regarding how much to pay for each of the intermediate goods and golf. Likewise, local residents, who face fewer and lower intermediate costs, will play relatively fewer rounds of high quality golf as compared to golf tourists. Similarly, for those golf tourists who bundle the entire vacation package, tourists who spend less on travel and lodging will play relatively more rounds of golf at the average course as compared to those tourists who spend more on travel and lodging.

It is important to reiterate that the golf consumer has the ability to separate intermediate costs from course quality costs; whether he does or does not is the focus of this study. In the case of purchasing grapes in New York, the quality and travel costs were automatically bundled. The purchasing agent at the store could not separate the travel costs from the quality costs. For the golf consumer, 
the costs of travel and quality can be separated. The issue is whether they will be or not.

\section{Review of Related Bundling Literature}

Gourville and Soman (2001) examined consumer behavior when products are bundled. They found that as more bundling of products takes place, consumption of those bundled products decreases. In sport for example, the bundling of tickets into season ticket packages results in fewer games attended even though tickets were purchased to all games. Therefore, bundling increases sales but decreases consumption. The potential impact on golf can be seen in the following example.

Golfer A has purchased a four-day golf package for $\$ 400$ while Golfer B has purchased four $\$ 100$ days of golf. Each golfer has paid the same for the golf experience. On the fourth day of golf, weather conditions are not ideal. Golfer A, who purchased his golf in a package, decides not to play. Golfer B, who has another golf day left at $\$ 100$, decides to play. As Gourville and Soman (2001) noted, there are financial ramifications at the course due to lost peripheral revenues like spending in the clubhouse or pro-shop when Golfer A decides not to play. More importantly, however, the authors noted that Golfer A's decision not to play is likely due to the masked cost of playing that occurs when products are bundled. For the consumer, determining the costs of individual items in a bundled package proves to be very difficult. As a result, the consumer tends to treat each item in a bundled package as if it were free. This provides a basis for Becker's (1971) argument that a golfer purchases a vacation package rather than a menu of travel, hotel, and golf costs.

Bauman (2004) examined the bundling of products as well. He posed that consumers would substitute only very similarly priced items. In his example, a high-quality French wine selling for $\$ 500$ a bottle as compared to a low quality French wine selling for $\$ 5$ a bottle will not have a higher consumption rate in the United States, when adding in transportation costs of $\$ 10$ per bottle, as compared to in France, because the wines are not close substitutes. However, when compared to similar California wines, the Alchian-Allen effect would factor in purchase decisions. If the price to produce a high-quality California wine is $\$ 500$ and a poor California wine is $\$ 5$, and the cost to ship French wines to California is $\$ 10$ per bottle, then a consumer could purchase three bottles of poor California wine ( $\$ 5$ each) for one bottle of poor French wine (\$15), or purchase 1.02 bottles of high-quality California wine ( $\$ 500)$ for one bottle of high-quality French wine (\$510). The substitution would be between the similarly priced California and French wines rather than between the poor-quality French wine and the highquality French wine. So, relative to golf spending, an average course (\$50) might not be a substitute for a highquality course ( $\$ 100)$, but instead a less expensive highquality course $(\$ 90)$, like the California wine, would be the logical substitute.

Razzolini, Shughart, and Tollison (2003) stated that a fixed cost, like the transportation cost, will reduce the price of a higher-quality item relative to a lower quality item only when it is sold by a company in a perfectly competitive, constant cost industry. Or, depending on the elasticities, relative prices between the high-quality and low-quality item do not change, or they change in favor of the lower-quality product. Relative prices would therefore govern consumption of the bundled product.

As the relative price of the product governs consumption of that product, it is important to examine Cowen and Tabarrok's (1995) study relating to product bundling. Cowen and Tabarrok argued that the consumer faces only one set of relative prices, those prices faced prior to going on vacation. After they arrive at a location, consumers would not look at the relative prices of products and purchase the cheaper product. Consumers would have known what the relative prices for the individual products were when making vacation price decisions in the first place. If the consumer wanted to go on a high-quality vacation, he or she would purchase high-quality goods. Conversely, if the consumer wanted to go on a low- quality vacation, he or she would purchase low-quality goods. Overall, Cowen and Tabarrok argued that Alchian-Allen would apply to golf tourists only if high- quality golf is strongly and positively related to a high-quality vacation. Importantly, Cowen and Tabarrok implied that the Alchian-Allen theorem here applied to the quality of the golf vacation, not to the quality of the golf course per se. 
Finally, Bertonazzi et al. (1993) argued that consumers purchase vacations a la Becker (1971) when they examined the relationship between distance traveled and football ticket quality at Clemson University. Under various tests for sensitivity, the authors found that people who traveled the farthest, thus having the highest travel costs (based upon their metric), purchased higher-quality football tickets. As it relates to the golf tourist, therefore, the whole golf vacation is one economic decision with many inputs. So, as the travel cost increases for the golfer, the relative cost of the high-end golf course decreases.

\section{Purpose of the Study}

The purpose of this study was to determine if golf tourists treated travel costs as sunk costs when deciding whether to play a great course or an average course or whether they treated travel costs as a bundled and thereby demanded great vacations as compared to average vacations. If travel costs are treated as sunk costs, by the first law of demand, golfers spending more on travel expenses will spend less on golf quality. However, if the third law of demand applies, golfers spending more on travel expenses will spend more for quality golf.

\section{Methodology}

Spending by golfers in the state of Ohio was measured to determine whether golfers and golf tourists treated travel costs as sunk costs when deciding whether to play a great course or an average course or whether they treated travel costs as a bundle and thereby demanded great vacations as compared to average vacations. Correia and Pintassilgo (2006) noted that determining characteristics of golf demand and quality choice is difficult as there are few studies relating to these topics. Mullin, Hardy, and Sutton (2000) stated that consumers often perceive that higher prices are related to higher quality while lower prices are related to lower quality; therefore, price was equated with quality in this study.

According to the Ohio Golf Course Guide (2003), there were over 750 public and private golf courses within the state of Ohio. The guide divided the golf courses into five meaningful geographic regions throughout the state. From these regions, the sample was drawn.
A stratified random sample was used to select 45 golf courses throughout the state for this study. Using a random number generator, courses were selected within each of the five geographic regions of the state and within three price points: lowest third, middle third and highest third. After the courses were randomly selected, each course in the sample was contacted to confirm the course's published greens fees. All of the greens fees were recorded and the sample was evaluated to ensure that there was a representative sample of each price category. In the process of calling the courses, it was discovered that a few of the courses selected for the sample no longer had golf available. Further, a few of the courses in each geographic region were found to have skewed the representative price categories within the sample. Therefore, these courses were removed from the original sample and replaced by additional randomly selected courses.

On various designated dates (split between weekends and weekdays), 15 contact information cards were distributed at the random sample of golf courses. Different sequences of days were used to ensure coverage of all the days of the week while placing greater relative emphasis on days that are typically characterized by heavy play. Golf course workers were asked to give a card to their customers as they either checked in or paid for their round(s). The cards directed patrons to a web site where they entered a password to complete a web-based survey.

After patrons had submitted their responses to the survey, their answers were posted to a database. The information in the database was collected following the completion of the survey timeframe and transferred to SPSS for analysis.

Golfers were asked about the course they played, their hometown (city and state), the number of rounds they played, the distance (in miles) they traveled to play, and how much they spent on the golf course and on activities related to their play that day. Multiple correlations were used to examine the relationship between distance traveled to play golf and the following expense variables: greens fee, cart fee, total greens and cart fee, total oncourse golf expenses, off-course golf-related spending, and total golf trip spending. Distance traveled was used as a proxy for travel expenses as discussed previously and in Bertonazzi et al. (1993). 


\section{Results}

Responses from all price points within all five regions of the state were received. In total, 376 golfers completed the on-line survey, a response rate of $56 \%$. Therefore, a reliability of $\pm 5 \%$ was achieved (Zikmund, 2003). Of the golfers that played a round in Ohio, 9.3\% $(\mathrm{n}=35)$ were classified as tourists. These golfers played $12.6 \%$ of all rounds within the state. For all golfers in the state, significant Pearson correlations $(\cdot=.01)$ were found between distance traveled and greens fee, greens and cart fee, total spending on the course, and total trip spending (see Table 1). An additional analysis of the data, looking only at those golfers defined as tourists by the state of Ohio, was conducted. Using the state's defininion, tourists included those individuals living out of state and playing golf within Ohio or those traveling over 100 miles to play golf within the state. For a golf tourist, at $=.01$, there were significant positive relationships found between distance traveled and greens fee, greens and cart fee, and total trip spending. At $=.05$, there were significant positive relationships found between distance traveled and cart fee and total course spending (see Table 1).

\section{Discussion, Implications, and Conclusions}

Data support the application of the Alchian-Allen theorem that as a fixed cost is added to the price of two similar products, the more expensive product becomes cheaper relative to the less expensive product in the context of the Ohio golf industry (Alchian \& Allen, 1964). The impact of the magnitude of travel costs on golf course quality costs becomes quite apparent when comparing the correlations for all golfers and golf tourists.

The relationship between distance traveled and costs is much greater when examining only golf tourists. For example, from Table 1, it can be seen that the Pearson correlation between distance traveled and greens fee was .549 for all golfers and .983 for tourists alone. For total trip costs, for all golfers the correlation was .226 and for tourists .951. The strength of these correlations for golf tourists, especially relating to greens fee, greens and cart fee, total course spending, and total spending, are so strong that controlling for other factors like income would not necessarily change the results.

Ohio golf course managers can utilize these findings in the market segmentation and target marketing of their courses. Mullin et al. (2000) define four bases upon which a product or service can segment consumers: (1) demographics, (2) psychographics, or consumers' commonly shared lifestyle and personality characteristics, (3) quantity of product usage, and (4) benefits of the product or service derived by consumers. Among several different demographic dimensions that can be used to segment a larger, heterogeneous market into a smaller, homogeneous one is geography.

The findings of this study indicate that Ohio golf course managers should utilize geographic segmentation in choosing to whom to market their course, based upon their products' price compared to area competitors, as shown by the strong, positive relationship $(\mathrm{r}=.983)$ found between distance traveled and cost of greens fees among Ohio golf course tourists. These results indicate that golf

Table 1. Correlations ( $r$ ) Between Distance Traveled and Spending Category for All Golfers and Golf Tourists

\begin{tabular}{lcc} 
Spending Category & All Golfers $(\mathbf{n}=376)$ & Golf Tourists $(\mathbf{n}=35)$ \\
Greens Fee & $.549^{* *}$ & $.983^{* *}$ \\
Cart Fee & .026 & $.360^{*}$ \\
Greens and Cart Fee & $.669^{* *}$ & $.983^{* *}$ \\
Total Course Spending & $.590^{* *}$ & $.986^{*}$ \\
Non-golf Trip Spending & .062 & .334 \\
Total Spending & $.226^{* *}$ & $.951^{* *}$ \\
${ }^{\star} \mathrm{p}<.05{ }^{* *} \mathrm{p}<.01$. & & \\
\hline
\end{tabular}


courses with high greens fees should consider targeting their marketing efforts toward tourists from considerable distances away, perhaps through golf and/or travel magazine advertisements for example, while courses with low greens fees should target local consumers with their marketing efforts, perhaps through local newspaper advertisements and similar marketing channels. In the same light, when creating a bundled package, tourism officials should match golf quality with vacation quality (Cowen \& Tabarrok, 1995) and target golf vacationers in a similar fashion, where packages with high costs should be marketed to tourists coming from considerable distances.

Golf packages must be created with caution however. Gourville and Soman (2001) stated that if a package user consumes only two of five tickets (in their example, tickets were to see a series of plays), he or she will be less likely to renew for next year as compared to a consumer that attended all or almost all of the performances. When bundling golf into a vacation package, the right mix of golf days to total vacation days must be calculated for consumers to ensure that the golfer will be satisfied after the vacation with the costs of the vacation package. Factors like weather conditions should be considered in the mix to avoid an oversubscription of golf, thereby decreasing the likelihood that the package's masked cost will lead to a golfer avoiding play on a poor weather condition day because he had played, for example, the three days previous.

Some resorts have attempted to address this issue. For example, rainy day policies at resorts may help mitigate lost revenue. A common rainy day policy at a golf resort provides a visitor an extra round of golf on their next visit if it rains during an entire day on their current visit. This type of policy could increase return visits while increasing satisfaction with the value of the bundled golf package.

Gourville and Soman (2001) further noted, however, that decisions not to play when purchasing golf via a bundled package may lead to a negative effect in sales that outweighs the income generated through the bundle. So even though the golfer paid for his or her day on the course, the revenue lost from that golfer's purchases at the course, whether in the clubhouse or pro-shop, may negatively affect the course's finances. For this reason, too, it is important for bundles to be structured properly.
Further research is needed to better determine the proper structure of these bundles.

Although these findings do not allow for generalization beyond the Ohio golf industry because of the populations examined, golf facilities in other locations could study the implications of the Alchian-Allen theorem to their own product through market research of their own customer base. Also, to add to and strengthen the findings, future studies in this area should control for other factors like income, fanaticism or avidity, age, and gender to get a better insight into who bundles decisions, why they bundle, and for what activities they bundle. An exploratory study to see if there are differences between those who do bundle and those who do not bundle would be beneficial to sport managers and marketers as well.

The analysis of spending by golf tourists in Ohio is not just about the support for the Alchian-Allen theorem. It is also about whether golf consumers bundle decisions together or separate them out sequentially. Here, the customer has a choice regarding whether to bundle costs or not. The data from this study indicates that most golfers, especially golf tourists, do bundle the quality costs with the intermediate costs of transportation, lodging, and food. Therefore, visitors play relatively more high quality rounds of golf in relation to lower quality rounds of golf than do locals.

\section{References}

Alchian, A., \& Allen, W. (1964). University economics. Belmont, CA: Wadsworth Publishing Co.

Bauman, Y. (2004). Shipping the good apples out: A new perspective. Economic Inquiry, 42, 534-536.

Becker, G. (1971). Economic theory. New York: Alfred Knopf.

Bertonazzi, E. P., Maloney, M. T., \& McCormick, R. E. (1993). Some evidence on the Alchian and Allen theorem: The third law of demand? Economic Inquiry, 31, 383-393.

Borcherding, T. E., \& Silberberg, E. (1978). Shipping the good apples out: The Alchian and Allen theorem reconsidered. Journal of Political Economy, 86, 131-138.

Correia, A., \& Pintassilgo, P. (2006). The golf players' motivations: The Algrave case. Tourism and Hospitality Research, 6, 227238.

Cowen, T., \& Tabarrok, A. (1995). Good grapes and bad lobsters: Applying the Alchian and Allen theorem. Economic Inquiry, 33, 253-256.

Gourville, J. T., \& Soman, D. (2001). The potential downside of bundling: How packaging services can hurt consumption. Cornell Hotel and Restaurant Administration Quarterly, 42(3), 29-37.

Hicks, L. A. (2006, April 27). Golf boom meets doom in county. The York Dispatch, p. B3. 
Mullin, B. J., Hardy, S., \& Sutton, W. A. (2000). Sport marketing (2nd ed.). Champaign, IL: Human Kinetics.

National Golf Foundation. (2003). Golf business almanac. Jupiter, FL: National Golf Foundation.

Ohio golf course guide. (2003). Powell, OH: Ohio Golf Course Owners Association.

Ohio Golf Course Owners Association. (2003). The economic impact of the golf course industry on the State of Ohio. Powell, OH: Ohio Golf Course Owners Association.

Razzolini, L., Shughart, W. F., II, \& Tollison, R. D. (2003). On the third law of demand. Economic Inquiry, 41, 292-298.

Zikmund, W. G. (2003). Business research methods (7th ed.). Mason, $\mathrm{OH}$ : Thompson South-Western. 